\title{
The Impact of Therapeutic Antibodies on the Management of Digestive Diseases: History, Current Practice, and Future Directions
}

\author{
M. Anthony Sofia ${ }^{1} \cdot$ David T. Rubin $^{1}$
}

Published online: 14 February 2017

(C) Springer Science+Business Media New York 2017

\begin{abstract}
The development of therapeutic antibodies represents a revolutionary change in medical therapy for digestive diseases. Beginning with the initial studies that confirmed the pathogenicity of cytokines in inflammatory bowel disease, the development and application of therapeutic antibodies brought challenges and insights into their potential and optimal use. Infliximab was the first biological drug approved for use in Crohn's disease and ulcerative colitis. The lessons learned from infliximab include the importance of immunogenicity and the influence of pharmacokinetics on disease response and outcomes. Building on this foundation, other therapeutic antibodies achieved approval for inflammatory bowel disease and many more are in development for several digestive diseases. In this review, we reflect on the history of therapeutic antibodies and discuss current practice and future directions for the field.
\end{abstract}

Keywords Therapeutic antibodies - Tumor necrosis factor alpha $\cdot$ Infliximab - Inflammatory bowel disease .

Therapeutic drug monitoring $\cdot$ Adalimumab

\section{Introduction}

The development of the technology to create targeted therapeutic antibodies marked a turning point in the ability for gastroenterologists to treat complex digestive diseases.

M. Anthony Sofia

masofia@uchicago.edu

1 Inflammatory Bowel Disease Center, University of Chicago Medicine, 5841 South Maryland Avenue, MC 4076, Chicago, IL 60637, USA
Since the technology was initially developed in the 1970s, therapeutic antibodies have taught physicians and scientists multiple lessons regarding the detailed workings of human physiology and pathology. The technology and scientific evidence have progressed so significantly that therapeutic antibodies now comprise the standard-of-care for inflammatory bowel disease. The clinical application of therapeutic antibodies provides opportunities and challenges for the field to refine treatments that improve the lives of patients. In this review, we reflect on the historical development of therapeutic antibodies for digestive diseases and consider the lessons learned that inform future therapies.

\section{Development of Infliximab}

The history of treatments for inflammatory bowel disease spans two eras, each of which was defined by revolutionary changes in medical management. The introduction of steroid treatment defines the first revolution, which enabled clinicians to manage the inflammation that propagated disease manifestations and was notably associated with a reduction in mortality associated with IBD [1]. The second revolution in treatments for inflammatory bowel disease began with the Food and Drug Administration (FDA) in the USA granting regulatory approval for infliximab. This era of therapeutic antibodies created new opportunities for safe and effective treatment, but also challenged researchers to consider a new paradigm for drug dosing, defining treatment targets, and conducting clinical trials. Infliximab represented the culmination of decades of rigorous basic science and translational research that ultimately benefited patients.

The development of infliximab began with the convergence of research on the cytokine tumor necrosis factor 
alpha $(\mathrm{TNF} \alpha)$ and the refinement of scalable chimeric antibody technology. TNF $\alpha$ exists in membrane-bound and soluble forms that bind to specific $\mathrm{TNF} \alpha$ receptors that mediate the release of numerous pro-inflammatory cytokines. Although the cytokine's name "tumor necrosis factor" refers to its initially observed ability to lyse murine tumor cells, later investigation revealed that it has significant effects on metabolism and inflammation [2-4]. While the biological significance of TNF $\alpha$ was under investigation, researchers created mouse hybridoma technology with the intention to generate specific antibodies for therapeutic application [5]. Nevertheless, initial human studies of antibodies created by this new technology faltered due to immune reactions directed against the therapeutic antibody itself [6]. Even at this early stage in development, the science revealed the challenge of maintaining tolerance to such therapeutic antibodies. Chimeric antibodies were developed to meet this challenge by fusing mouse variable domain regions to human constant regions [7]. By the early 1990 s, the stage was set with the emerging understanding of TNF $\alpha$ in inflammatory diseases and the technology to target this protein with chimeric antibodies. Soon, infliximab (initially called cA2), an antibody with high in vitro specificity for soluble and transmembrane-bound TNFa was developed [8-10].

Promising findings in model systems progressed to the use of infliximab in human subjects with inflammatory bowel disease. Initial studies of infliximab for Crohn's disease revealed remarkable efficacy, with a majority of patients achieving normalization of Crohn's disease activity index scores and endoscopic healing of ulcerations [11]. Large, randomized controlled trials of infliximab in Crohn's disease and ulcerative colitis further supported these findings, demonstrating benefit for both induction and maintenance of response and remission [12-17]. Infliximab was granted orphan drug status and became the first FDAapproved medication for Crohn's disease in 1998 [18, 19]. It was also the first FDA-approved medication for Crohn's disease for which long-term safety data were available. Several studies now report that infliximab is safe and well tolerated over years of therapy [20-22]. Notably, infliximab does not increase the risk for malignancies or for mortality [22, 23].

While infliximab generated enthusiasm for its efficacy, a significant proportion of patients did not respond to this therapy. One of the early reasons identified for this problem was due to the development of antidrug antibodies related to the immunogenic potential of the antibody, a challenge that has been recognized since the first clinical use of therapeutic antibodies. Antibodies to infliximab are associated with an increased risk for infusion reactions and a decreased duration of response [24]. Adding an immunomodulator such as azathioprine can improve efficacy and reduce immunogenicity of infliximab $[25,26]$. Some data also suggest that adding an immunomodulator can overcome the formation of antibodies to infliximab and recapture efficacy [27]. These findings were translated into the use of combination therapy in regular clinical practice.

The additional reason for lack of or loss of response to infliximab was due to the pharmacokinetics of infliximab and other monoclonal antibodies. Data derived from the pivotal trial of infliximab in Crohn's disease revealed that episodic treatments are less effective than scheduled maintenance doses [28]. A high inflammatory burden also contributes to low serum drug levels [29, 30]. Drug clearance is influenced by high tissue TNF $\alpha$ concentrations, low serum albumin concentration, and infliximab loss into the stool [31-34]. In response to these findings, proactive drug monitoring became a subject of intense investigation; for example, accelerated infliximab dosing for acute, severe ulcerative colitis can reduce short-term colectomy rates [35]. Meanwhile, a proactive strategy for therapeutic drug monitoring and drug level-targeted infliximab dosing led to a greater probability of clinical remission in Crohn's disease [36]. These findings solidified the importance of pharmacokinetic monitoring in the optimal management of infliximab therapy, which now serves as a model for the management of disease treatment with other therapeutic antibodies.

The development of infliximab also introduced objective disease outcomes and novel ethical considerations that advanced clinical trial design. Objective disease outcomes are now an integral component of any clinical trial for inflammatory bowel disease in part due to the data derived from trials of infliximab. Clinical trials of infliximab in ulcerative colitis demonstrated efficacy for inducing grossly visible mucosal healing, termed endoscopic remission [15]. Later studies showed that endoscopic remission was associated with superior clinical outcomes $[37,38]$. At present, objective outcomes are increasingly being used to support the efficacy of new therapies [39].

At the same time, new ethical considerations emerged from the pivotal trial of infliximab in Crohn's disease. Investigators demonstrated significant benefit to scheduled infliximab dosing over episodic dosing [16, 28]. By the end of this study, $30 \%$ of patients with episodic dosing developed antibodies to infliximab that considerably increase the risk for decreased efficacy and the development of hypersensitivity reactions [40, 41]. Clinical trial participants received the drug during the trial, but could not continue the drug outside the trial until the drug was FDA approved, effectively providing episodic treatment with consequent induced immunity against the therapy. The volunteer subjects of initial clinical trials had contributed to the advancement of the field, but due to their limited exposure and high risk of immunogenicity, would then be unable to 
benefit from the therapy after it became available in the clinic. With this new knowledge, ethically sound clinical trial design changed to require the option to receive the study drug beyond the duration of the trial [42]. The experience with infliximab altered the development of drug investigational methods that now serve as the standard for future clinical trials in inflammatory bowel disease.

As the first therapeutic antibody for use in inflammatory bowel disease, infliximab is almost as important for the challenges it presented as it is for its efficacy (Table 1). By addressing these challenges, the study of infliximab in inflammatory bowel disease ushered in a new paradigm for the management of IBD specifically and other digestive diseases more generally.

\section{Currently Available Therapeutic Antibodies in Digestive Diseases}

\section{Inflammatory Bowel Disease}

Several other therapeutic antibodies are now approved for inflammatory bowel disease in the years following the regulatory approval of infliximab. The human-derived anti$\mathrm{TNF} \alpha$ antibody, adalimumab, was originally developed for therapy of rheumatoid arthritis and represents the next significant development in therapeutic antibodies in IBD. Adalimumab was the first therapeutic antibody developed using phage display technology, which enables rapid screening of candidate antibodies for specificity toward a target protein [43]. It was also the first human antibody approved for use in inflammatory bowel disease. Clinical trials showed that adalimumab is effective for treating Crohn's disease and ulcerative colitis [44-51]. Similarly to infliximab, additional pharmacokinetic studies showed that antibodies to adalimumab predicted Crohn's disease recurrence [52]. As well, adding an immunomodulator for combination therapy may recapture response to adalimumab [53]. With multiple approved and available anti$\mathrm{TNF} \alpha$ antibodies, it is common that patients will have treatment with several agents within the class. Previous response to infliximab is a significant predictor of response to adalimumab in ulcerative colitis [54]. Similarly, prior development of antibodies to infliximab is associated with later developing antibodies to adalimumab [55]. Although there have been no head-to-head studies, a recent retrospective comparative effectiveness study suggests that infliximab and adalimumab are of comparable effectiveness [56].

In addition to adalimumab, the class of anti-TNFa antibodies for inflammatory bowel disease continued to expand and now includes certolizumab pegol and golimumab. Certolizumab pegol differs from infliximab and adalimumab in that it is composed of a humanized TNF $\alpha$ specific Fab conjugated to polyethylene glycol [57]. Humanized antibodies are created by replacing human complementarity-determining regions with mouse-derived components, while maintaining the remainder of the human antibody [58]. Humanization in theory may lead to a lower frequency of developing antidrug antibodies [59]. Certolizumab pegol is approved for use in Crohn's disease to achieve induction and maintenance of symptomatic response and improvement of quality-of-life measures [60-66]. Certolizumab pegol may differ from other TNFa antibodies since, due to its structure, it does not induce apoptosis in monocytes. It also may not achieve adequate therapeutic drug concentrations with standard dosing $[67,68]$. Whereas certolizumab pegol is approved only for moderate-severe Crohn's disease, golimumab is a human $\mathrm{TNF} \alpha$ antibody approved for moderate-severe ulcerative colitis. Clinical trials demonstrated efficacy with achieving clinical remission and mucosal healing specified as "endoscopic improvement" [69, 70].

The latest advances in therapeutic antibodies for inflammatory bowel disease target other mechanisms of intestinal inflammation. Natalizumab is a humanized antibody directed against $\alpha 4$ integrin and therefore inhibits both $\alpha 4 \beta 7$ (target is MAdCAM) and $\alpha 4 \beta 1$ (target is VCAM). It is approved for treating both multiple sclerosis and Crohn's disease. This was the first therapeutic antibody to target leukocyte adhesion molecules to treat Crohn's disease [71-73]. Natalizumab is effective, but since it carries a small risk for reactivation of the John Cunningham (JC) polyoma virus, it has been restricted for use only

Table 1 Lessons learned from the application of infliximab in inflammatory bowel disease

\section{Lessons learned from infliximab}

Maintenance therapy is superior to episodic therapy

Combination therapy with an immunomodulator can reduce immunogenicity

Therapeutic drug monitoring can improve drug dosing

Pharmacokinetics of drug clearance is influenced by high inflammatory burden and stool protein losses

Objective disease outcomes are realistic and preferred for clinical trial design

Ethical clinical trial design includes the option to continue the study drug beyond the trial 
after anti-TNF $\alpha$ therapies have failed [73]. Further investigation led to the development of vedolizumab, a humanized antibody that targets $\alpha 4 \beta 7$ integrin, which is specifically active in the intestinal endothelium [74]. Vedolizumab is effective for the induction and maintenance of remission for both moderate-severe Crohn's disease and moderate-severe ulcerative colitis $[75,76]$. In addition to leukocyte adhesion, IL-12 and IL-23 have emerged as therapeutic targets in IBD. Ustekinumab is a human antibody targeting the p40 subunit of both IL-12 and IL-23 that has demonstrated efficacy for treating moderate-severe Crohn's disease [77, 78]. It was originally FDA approved for use in psoriasis and recently achieved regulatory approval for Crohn's disease [79].

\section{Liver Disease}

Therapeutic antibodies are useful in the management of liver transplantation. Muromonab CD-3 (OKT-3) was the first monoclonal antibody approved for clinical use, originally developed to treat acute rejection in liver transplant recipients. Although it was efficacious for reversing steroid-resistant acute rejection and preserving renal function, in comparison with the standard-of-care for immunosuppression in the 1980s, $\sim 85 \%$ of patients developed antibodies to muromonab due to its murine origin, which severely limited its utility and increased risks of infusion reactions [80, 81]. In the 1990s, interleukin-2 receptor antagonism (IL-2RA) emerged as an alternative therapeutic strategy for reducing the likelihood of acute rejection and potentially lessening exposure to toxicity from steroids and calcineurin inhibitors $[82,83]$. IL-2 activates lymphocyte proliferation. Basiliximab and daclizumab are therapeutic antibodies that target the IL-2 receptor $\alpha$ chain, also called CD25. Basiliximab is a chimeric antibody, whereas daclizumab is a humanized antibody. Notably, basiliximab clearance correlates with the cumulative volume of ascites drained in the first week following dosing [84]. In adult liver transplant patients, the number needed to treat (NNT) to prevent one acute rejection is 15 , whereas the NNT to prevent one steroid-resistant rejection is 29 [85]. Nevertheless, the NNT in pediatric liver transplants to prevent one episode of acute rejection is 3.6 [86]. Despite these short-term benefits, systematic reviews of IL-2RA in adult and pediatric liver transplants did not find a difference for either graft loss or patient death.

\section{Future Directions}

\section{Inflammatory Bowel Disease}

The future of therapeutic antibodies for inflammatory bowel disease includes continued development of anti- integrin antibodies, antibodies directed against other cytokines, and the introduction of biosimilar medications.

Building on the success of natalizumab and vedolizumab, etrolizumab is the latest drug in development that targets leukocyte trafficking. Etrolizumab is a humanized antibody targeting the $\beta-7$ subunit of $\alpha-4-\beta-7$ and $\alpha-E-\beta-7$ integrins delivered by self-injection. It is efficacious and safe for ulcerative colitis according to phase I and II studies [87, 88]. It is now in phase III clinical trials for Crohn's disease (NCT02394028) and ulcerative colitis (NCT02165215, NCT02171429, NCT02100696). There is also an ongoing study of etrolizumab in combination with adalimumab for ulcerative colitis (NCT02163759) and another comparing etrolizumab to infliximab for ulcerative colitis (NCT02136069). The results of these studies may not only increase therapeutic options for inflammatory bowel disease, but they have the potential to introduce new strategies for combining therapeutic antibodies and personalizing treatment.

In addition to $\mathrm{TNF} \alpha$ and lymphocyte adhesion molecules, there are other therapeutic targets under investigation including IL-23 and matrix metalloproteinase (MMP)9. Following the recent approval of ustekinumab for Crohn's disease, monoclonal antibodies that specifically target IL-23 are in various stages of development (AMG 139, BI 655066, MEDI 2070). Alternatively, GS 5745 is a humanized antibody targeting MMP-9, a proteolytic enzyme whose expression and activity correlate with ulcerative colitis disease activity $[89,90]$. It is currently in a phase II clinical trial for Crohn's disease (NCT02405442). A combined phase II/III clinical trial for ulcerative colitis (NCT02520284) was discontinued due to meeting pre-specified futility criteria.

Biosimilars are biological products that are highly similar but not identical to a reference biological drug and have no clinically meaningful differences in efficacy or safety. Biosimilar substitutes for therapeutic antibodies commonly used in inflammatory bowel disease are already achieving global regulatory approval. Their emergence in the marketplace presents important challenges not yet addressed in the history of therapeutic antibodies since they do not share the identical chemical structure with the originator compound and thus have expected differences in posttranslational glycosylation. Since biosimilar medications share similar immunogenicity with the originator compound, unidirectional switching is tolerated for infliximab and adalimumab biosimilars [91-94]. Nevertheless, there is no evidence to support true interchangeability, which requires the safe and tolerable switch from originator to biosimilar and back again. Recent studies of infliximab biosimilars indicated efficacy and safety similar to the infliximab originator [95-97]. Importantly, antibodies to infliximab also recognize biosimilar infliximab [98]. 
These data, though reassuring, are not conclusive. Additionally, biosimilar medications approved for other indications have received regulatory approval without specific studies in patients with inflammatory bowel disease, a concept known as "extrapolation". An adalimumab biosimilar was approved in 2016 based on evidence derived from studies in rheumatoid arthritis and psoriasis [99]. It has now achieved regulatory approval from the FDA, but importantly is only approved as a biosimilar, not as an interchangeable product [100]. Post-approval pharmacovigilance will be important for determining the optimal use of biosimilar medications. Future studies will evaluate the consequences of elective switching between biosimilar and originator compounds. It is also unknown whether this exchange is exclusively unidirectional. These and other unforeseen challenges await clinicians as biosimilar products are brought to market.

\section{C. difficile Colitis}

Therapeutic antibodies are now the subject of investigation for application to Clostridium difficile colitis. C. difficile infection can complicate the use of broad-spectrum antibiotics, causing a severe infectious toxigenic colitis rising in incidence and incurring significant morbidity and mortality [101]. Human monoclonal antibodies that neutralize $C$. difficile toxins $\mathrm{A}$ and $\mathrm{B}$, lower TNFa levels and improve survival in preclinical mouse models are currently under investigation [102-104]. A phase II study compared treatment with monoclonal antibodies against toxins $\mathrm{A}$ and B combined with standard antibiotic treatment to antibiotic treatment alone. The treatment group had lower recurrence incidence, particularly in patients with recurrent $C$. difficile infection [105]. Recently, bezlotoxumab, a monoclonal antibody against $C$. difficile toxin $\mathrm{B}$, was recommended for approval based on phase III trial data presented to the FDA [106]. However, enrollment for the trial arm of actoxumab, the antibody directed against $C$. difficile toxin $\mathrm{A}$, ended early by the recommendation of the data monitoring committee following an interim analysis. In the published FDA briefing document, the presented data show bezlotoxumab is effective for reducing the recurrence of $C$. difficile infection compared to placebo when added to standard-of-care treatment. Bezlotoxumab was not immunogenic in both healthy subjects and patients with $C$. difficile infection. Despite these encouraging data, continued research will help determine the optimal indication for bezlotoxumab in the treatment of $C$. difficile infection.

\section{Liver Disease}

There are ongoing studies investigating novel uses for the therapeutic antibodies vedolizumab and simtuzumab in liver disease. Although vedolizumab is already approved for use in ulcerative colitis and Crohn's disease, a belief exists that its mechanism of action may confer efficacy for the treatment of primary sclerosing cholangitis, prompting the planning of a clinical trial to further investigate this supposition [107, 108]. In addition to vedolizumab, simtuzumab is a novel humanized therapeutic antibody that targets the lysyl oxidase-like 2 (LOXL2) enzyme, the expression of which correlates with hepatic fibrosis. Clinical trials are currently underway to determine whether simtuzumab can prevent progression of fibrosis in nonalcoholic steatohepatitis, fibrotic liver disease secondary to viral hepatitis, and primary sclerosing cholangitis [109, 110].

\section{Eosinophilic Esophagitis}

The allergic mechanism of eosinophilic esophagitis is also a potential target for therapeutic antibodies. Although the monoclonal antibody against IL-5, mepolizumab is approved for asthma with an eosinophilic phenotype, and studies have considered its use for eosinophilic esophagitis [111]. Limited studies demonstrate that mepolizumab reduces intraepithelial eosinophils in children and adults, though efficacy with reducing symptoms is lacking [112, 113].

\section{Pharmacoeconomic Considerations of Biological Therapy}

Although therapeutic antibodies are a significant cost driver in modern healthcare, their use is an investment in improved patient outcomes and cost-effective strategies are emerging for better resource utilization. As biological therapies for inflammatory bowel disease become more common, the costs of caring for this patient population shift from hospitalizations and surgeries to medical therapy [114, 115] considering the lower odds of hospitalization associated with biological drug use [116]. It is vitally important to understand that this new paradigm represents an ethically optimal change from reactive, illness-driven care to proactive, preventative care. Unfortunately, the investment cost increases scrutiny from payers that unfortunately choose to withhold approval of effective therapy in order to increase short-term cost savings. The field is reacting to shortsighted cost containment from payers by developing the tools to improve efficient use of scarce resources. The first step in efficient care is choosing the appropriate initial drug. There is evidence to support infliximab as the current first choice due to its relative costeffectiveness, although this calculation can vary based on drug and infusion-related costs [117]. Further, dose optimization can reduce over- and under-treatment. Greater 
Table 2 Available therapeutic antibodies with mechanism of action by disease state
Table 3 Emerging therapeutic antibodies with mechanism of action by disease state

\begin{tabular}{lll}
\hline Disease & Mechanism of action & Available therapeutic antibodies \\
\hline Crohn's disease & Anti-TNF $\alpha$ & Infliximab \\
& & Adalimumab \\
& & Certolizumab pegol \\
& Anti- $\alpha 4$ integrin & Natalizumab \\
& Anti- $\alpha 4 \beta 7$ integrin & Vedolizumab \\
Ulcerative colitis & Anti-IL-12/23 & Ustekinumab \\
& Anti-TNF $\alpha$ & Infliximab \\
& & Adalimumab \\
& & Golimumab \\
Liver transplantation & Anti- $\alpha 4 \beta 7$ integrin & Vedolizumab \\
& Anti-CD3 & Muromonab \\
& Anti-IL-2 receptor & Basiliximab \\
& & Daclizumab
\end{tabular}

$T N F \alpha$ tumor necrosis factor $\alpha$

\begin{tabular}{lll}
\hline Disease & Mechanism of action & Emerging therapeutic antibodies \\
\hline Inflammatory bowel disease & Anti- $\beta$ 7 integrin subunit & Etrolizumab \\
& Anti-IL-23 & AMG 139 \\
& & BI 655066 \\
& & MEDI 2070 \\
& Anti-MMP-9 & GS 5745 \\
C. difficile colitis & Anti- $C$. difficile toxin B & Bezlotoxumab \\
Primary sclerosing cholangitis & Anti- $\alpha$ 4 $\beta 7$ integrin & Vedolizumab \\
& Anti-LOXL2 & Simtuzumab \\
Nonalcoholic steatohepatitis & Anti-LOXL2 & Simtuzumab \\
Eosinophilic esophagitis & Anti-IL-5 & Mepolizumab \\
\hline
\end{tabular}

MMP-9 matrix metalloproteinase 9, LOXL2 lysyl oxidase-like 2 understanding of pharmacokinetics is leading to individualized drug dosing that is cost saving and clinically efficient $[118,119]$. Furthermore, targeting objective disease outcomes also improves effective drug dosing and costeffectiveness [120].

\section{Conclusions}

The development of therapeutic antibodies is among the greatest advancements in modern medicine. Their impact is particularly notable in the digestive diseases. While initially becoming established in inflammatory bowel disease, indications for the use of therapeutic antibodies are expanding into more disease states and targeting a growing number of cellular mechanisms. The development of infliximab exemplifies the value of rational basic science, preclinical, and post-approval research that has broad implications. Currently available treatments expand and reinforce this new paradigm (Table 2). Finally, emerging therapies will continue to challenge investigators and clinicians to provide disease-specific, proactive, and efficient medical treatment (Table 3). The true impact of therapeutic antibodies resides in their ability to alter the natural history of these complex diseases and improve the lives of patients around the world.

\section{References}

1. Ritchie J, Powell-Tuck T, Lennard-Jones JE. Clinical outcome of the first ten years of ulcerative colitis and proctitis. Lancet. 1978;311:1140-1143.

2. Carswell EA, Old LJ, Kassel RL, Green S, Fiore N, Williamson B. An endotoxin-induced serum factor that causes necrosis of tumors. Proc Natl Acad Sci USA. 1975;72:3666-3670.

3. Beutler B, Greenwald D, Hulmes JD, et al. Identity of tumour necrosis factor and the macrophage-secreted factor cachectin. Nature. 1985;316:552-554. 
4. Simpson SJ, Hollander GA, Mizoguchi E, et al. Expression of pro-inflammatory cytokines by TCR alpha beta + and TCR gamma delta $+\mathrm{T}$ cells in an experimental model of colitis. Eur J Immunol. 1997;27:17-25.

5. Kohler G, Milstein C. Continuous cultures of fused cells secreting antibody of predefined specificity. Nature. 1975;256:495-497.

6. Shawler DL, Bartholomew RM, Smith LM, Dillman RO. Human immune response to multiple injections of murine monoclonal IgG. J Immunol (Baltimore, MD: 1950). 1985;135:1530-1535.

7. Boulianne GL, Hozumi N, Shulman MJ. Production of functional chimaeric mouse/human antibody. Nature. 1984;312:643-646.

8. Knight DM, Trinh $\mathrm{H}$, Le J, et al. Construction and initial characterization of a mouse-human chimeric anti-TNF antibody. Mol Immunol. 1993;30:1443-1453.

9. Siegel SA, Shealy DJ, Nakada MT, et al. The mouse/human chimeric monoclonal antibody cA2 neutralizes TNF in vitro and protects transgenic mice from cachexia and TNF lethality in vivo. Cytokine. 1995;7:15-25.

10. Scallon BJ, Moore MA, Trinh H, Knight DM, Ghrayeb J. Chimeric anti-TNF-alpha monoclonal antibody cA2 binds recombinant transmembrane TNF-alpha and activates immune effector functions. Cytokine. 1995;7:251-259.

11. van Dullemen HM, van Deventer SJ, Hommes DW, et al. Treatment of Crohn's disease with anti-tumor necrosis factor chimeric monoclonal antibody (cA2). Gastroenterology. 1995;109:129-135.

12. Targan SR, Hanauer SB, van Deventer SJ, et al. A short-term study of chimeric monoclonal antibody cA2 to tumor necrosis factor alpha for Crohn's disease. Crohn's Disease cA2 Study Group. N Engl J Med. 1997;337:1029-1035.

13. Present DH, Rutgeerts $\mathrm{P}$, Targan $\mathrm{S}$, et al. Infliximab for the treatment of fistulas in patients with Crohn's disease. $N$ Engl J Med. 1999;340:1398-1405.

14. Sands BE, Tremaine WJ, Sandborn WJ, et al. Infliximab in the treatment of severe, steroid-refractory ulcerative colitis: a pilot study. Inflamm Bowel Dis. 2001;7:83-88.

15. Rutgeerts P, Sandborn WJ, Feagan BG, et al. Infliximab for induction and maintenance therapy for ulcerative colitis. $N$ Engl J Med. 2005;353:2462-2476.

16. Hanauer SB, Feagan BG, Lichtenstein GR, et al. Maintenance infliximab for Crohn's disease: the ACCENT I randomised trial. Lancet. 2002;359:1541-1549.

17. Rutgeerts P, D'Haens G, Targan S, et al. Efficacy and safety of retreatment with anti-tumor necrosis factor antibody (infliximab) to maintain remission in Crohn's disease. Gastroenterology. 1999;117:761-769.

18. Nightingale SL. From the food and drug administration. JAMA. 1998;280:1128.

19. Kornbluth A. Infliximab approved for use in Crohn's disease: a report on the FDA GI Advisory Committee conference. Inflamm Bowel Dis. 1998;4:328-329.

20. Fidder H, Schnitzler F, Ferrante M, et al. Long-term safety of infliximab for the treatment of inflammatory bowel disease: a single-centre cohort study. Gut. 2009;58:501-508.

21. Caspersen S, Elkjaer M, Riis L, et al. Infliximab for inflammatory bowel disease in Denmark 1999-2005: clinical outcome and follow-up evaluation of malignancy and mortality. Clin Gastroenterol Hepatol. 2008;6:1212-1217. (quiz 1176).

22. Lichtenstein GR, Rutgeerts P, Sandborn WJ, et al. A pooled analysis of infections, malignancy, and mortality in infliximaband immunomodulator-treated adult patients with inflammatory bowel disease. Am J Gastroenterol. 2012;107:1051-1063.
23. Lichtenstein GR, Feagan BG, Cohen RD, et al. Serious infection and mortality in patients with Crohn's disease: more than 5 years of follow-up in the TREAT registry. Am J Gastroenterol. 2012;107:1409-1422.

24. Baert F, Noman M, Vermeire S, et al. Influence of immunogenicity on the long-term efficacy of infliximab in Crohn's disease. N Engl J Med. 2003;348:601-608.

25. Colombel JF, Sandborn WJ, Reinisch W, et al. Infliximab, azathioprine, or combination therapy for Crohn's disease. $N$ Engl J Med. 2010;362:1383-1395.

26. Panaccione R, Ghosh S, Middleton S, et al. Combination therapy with infliximab and azathioprine is superior to monotherapy with either agent in ulcerative colitis. Gastroenterology. 2014;146:392.e393-400.e393.

27. Ben-Horin S, Waterman M, Kopylov U, et al. Addition of an immunomodulator to infliximab therapy eliminates antidrug antibodies in serum and restores clinical response of patients with inflammatory bowel disease. Clin Gastroenterol Hepatol. 2013;11:444-447.

28. Rutgeerts P, Feagan BG, Lichtenstein GR, et al. Comparison of scheduled and episodic treatment strategies of infliximab in Crohn's disease. Gastroenterology. 2004;126:402-413.

29. Magro F, Rodrigues-Pinto E, Santos-Antunes J, et al. High C-reactive protein in Crohn's disease patients predicts nonresponse to infliximab treatment. J Crohns Colitis. 2014;8:129-136.

30. Brandse JF, Mathot RA, van der Kleij D, et al. Pharmacokinetic features and presence of antidrug antibodies associate with response to infliximab induction therapy in patients with moderate to severe ulcerative colitis. Clin Gastroenterol Hepatol. 2016;14:251.e252-258.e252.

31. Brandse JF, van den Brink GR, Wildenberg ME, et al. Loss of infliximab into feces is associated with lack of response to therapy in patients with severe ulcerative colitis. Gastroenterology. 2015;149:350.e352-355.e352.

32. Atreya R, Neumann $H$, Neufert $C$, et al. In vivo imaging using fluorescent antibodies to tumor necrosis factor predicts therapeutic response in Crohn's disease. Nat Med. 2014;20:313-318.

33. Yarur AJ, Jain A, Sussman DA, et al. The association of tissue anti-TNF drug levels with serological and endoscopic disease activity in inflammatory bowel disease: the ATLAS study. Gut. 2016;65:249-255.

34. Fasanmade AA, Adedokun OJ, Olson A, Strauss R, Davis HM. Serum albumin concentration: a predictive factor of infliximab pharmacokinetics and clinical response in patients with ulcerative colitis. Int J Clin Pharmacol Ther. 2010;48:297-308.

35. Gibson DJ, Heetun ZS, Redmond CE, et al. An accelerated infliximab induction regimen reduces the need for early colectomy in patients with acute severe ulcerative colitis. Clin Gastroenterol Hepatol. 2015;13:330.e331-335.e331.

36. Vande Casteele N, Ferrante M, Van Assche G, et al. Trough concentrations of infliximab guide dosing for patients with inflammatory bowel disease. Gastroenterology. 2015;148:1320.e1323-1329. e1323.

37. Froslie KF, Jahnsen J, Moum BA, Vatn MH. Mucosal healing in inflammatory bowel disease: results from a Norwegian population-based cohort. Gastroenterology. 2007;133:412-422.

38. Meucci G, Fasoli R, Saibeni S, et al. Prognostic significance of endoscopic remission in patients with active ulcerative colitis treated with oral and topical mesalazine: a prospective, multicenter study. Inflamm Bowel Dis. 2012;18:1006-1010.

39. Hindryckx P, Baert F, Hart A, et al. Clinical trials in ulcerative colitis: a historical perspective. J Crohns Colitis. 2015;9:580-588.

40. Hanauer SB. The ethics of phase I trials of biologic agents. Nat Clin Pract Gastroenterol Hepatol. 2008;5:533. 
41. Sandborn WJ. Preventing antibodies to infliximab in patients with Crohn's disease: optimize not immunize. Gastroenterology. 2003;124:1140-1145.

42. Rubin DT, Becker S, Siegler M. Ethical considerations for clinical trials in inflammatory bowel disease. Gastroenterol Hepatol. 2014;10:37-41.

43. Winter G, Griffiths AD, Hawkins RE, Hoogenboom HR. Making antibodies by phage display technology. Аnпu Rev Immunol. 1994;12:433-455.

44. Afif W, Leighton JA, Hanauer SB, et al. Open-label study of adalimumab in patients with ulcerative colitis including those with prior loss of response or intolerance to infliximab. Inflamm Bowel Dis. 2009;15:1302-1307.

45. Reinisch W, Sandborn WJ, Hommes DW, et al. Adalimumab for induction of clinical remission in moderately to severely active ulcerative colitis: results of a randomised controlled trial. Gut. 2011;60:780-787.

46. Sandborn WJ, van Assche G, Reinisch W, et al. Adalimumab induces and maintains clinical remission in patients with moderate-to-severe ulcerative colitis. Gastroenterology. 2012;142:257.e251-253-265.e251-253.

47. Sandborn WJ, Hanauer S, Loftus EV Jr, et al. An open-label study of the human anti-TNF monoclonal antibody adalimumab in subjects with prior loss of response or intolerance to infliximab for Crohn's disease. Am J Gastroenterol. 2004;99: 1984-1989.

48. Papadakis KA, Shaye OA, Vasiliauskas EA, et al. Safety and efficacy of adalimumab (D2E7) in Crohn's disease patients with an attenuated response to infliximab. Am J Gastroenterol. 2005;100:75-79.

49. Hanauer SB, Sandborn WJ, Rutgeerts P, et al. Human anti-tumor necrosis factor monoclonal antibody (adalimumab) in Crohn's disease: the CLASSIC-I trial. Gastroenterology. 2006;130: 323-333. (quiz 591).

50. Colombel JF, Sandborn WJ, Rutgeerts P, et al. Adalimumab for maintenance of clinical response and remission in patients with Crohn's disease: the CHARM trial. Gastroenterology. 2007;132:52-65.

51. Sandborn WJ, Hanauer SB, Rutgeerts P, et al. Adalimumab for maintenance treatment of Crohn's disease: results of the CLASSIC II trial. Gut. 2007;56:1232-1239.

52. Baert F, Kondragunta V, Lockton S, et al. Antibodies to adalimumab are associated with future inflammation in Crohn's patients receiving maintenance adalimumab therapy: a post hoc analysis of the Karmiris trial. Gut. 2016;65:1126-1131.

53. Ong DE, Kamm MA, Hartono JL, Lust M. Addition of thiopurines can recapture response in patients with Crohn's disease who have lost response to anti-tumor necrosis factor monotherapy. J Gastroenterol Hepatol. 2013;28:1595-1599.

54. Baert F, Vande Casteele N, Tops S, et al. Prior response to infliximab and early serum drug concentrations predict effects of adalimumab in ulcerative colitis. Aliment Pharmacol Ther. 2014;40:1324-1332.

55. Frederiksen MT, Ainsworth MA, Brynskov J, Thomsen OO, Bendtzen K, Steenholdt C. Antibodies against infliximab are associated with de novo development of antibodies to adalimumab and therapeutic failure in infliximab-to-adalimumab switchers with IBD. Inflamm Bowel Dis. 2014;20:1714-1721.

56. Ananthakrishnan AN, Cagan A, Cai T, et al. Comparative Effectiveness of Infliximab and Adalimumab in Crohn's disease and ulcerative colitis. Inflamm Bowel Dis. 2016;22:880-885.

57. Chapman AP. PEGylated antibodies and antibody fragments for improved therapy: a review. Adv Drug Deliv Rev. 2002;54: 531-545.
58. Jones PT, Dear PH, Foote J, Neuberger MS, Winter G. Replacing the complementarity-determining regions in a human antibody with those from a mouse. Nature. 1986;321:522-525.

59. Hwang WY, Foote J. Immunogenicity of engineered antibodies. Methods. 2005;36:3-10.

60. Schreiber S, Rutgeerts P, Fedorak RN, et al. A randomized, placebo-controlled trial of certolizumab pegol (CDP870) for treatment of Crohn's disease. Gastroenterology. 2005;129:807-818.

61. Sandborn WJ, Schreiber S, Feagan BG, et al. Certolizumab pegol for active Crohn's disease: a placebo-controlled, randomized trial. Clin Gastroenterol Hepatol. 2011;9:670.e673-678.e673.

62. Sandborn WJ, Feagan BG, Stoinov S, et al. Certolizumab pegol for the treatment of Crohn's disease. $N$ Engl J Med. 2007;357:228-238.

63. Schreiber S, Khaliq-Kareemi M, Lawrance IC, et al. Maintenance therapy with certolizumab pegol for Crohn's disease. $N$ Engl J Med. 2007;357:239-250.

64. Rutgeerts P, Schreiber S, Feagan B, Keininger DL, O’Neil L, Fedorak RN. Certolizumab pegol, a monthly subcutaneously administered $\mathrm{Fc}$-free anti-TNF $\alpha$, improves health-related quality of life in patients with moderate to severe Crohn's disease. Int $J$ Colorectal Dis. 2008;23:289-296.

65. Feagan BG, Reilly MC, Gerlier L, Brabant Y, Brown M, Schreiber S. Clinical trial: the effects of certolizumab pegol therapy on work productivity in patients with moderate-to-severe Crohn's disease in the PRECiSE 2 study. Aliment Pharmacol Ther. 2010;31:1276-1285.

66. Lang L. FDA approves Cimzia to treat Crohn's disease. Gastroenterology. 2008;134:1819.

67. Nesbitt A, Fossati G, Bergin M, et al. Mechanism of action of certolizumab pegol (CDP870): in vitro comparison with other anti-tumor necrosis factor alpha agents. Inflamm Bowel Dis. 2007;13:1323-1332.

68. Casteele NV, Stitt L, Spearman M, et al. Sa1937 exposure-response relationship for certolizumab pegol during the induction phase in patients. Gastroenterology. 2016;150:S409.

69. Sandborn WJ, Feagan BG, Marano C, et al. Subcutaneous golimumab induces clinical response and remission in patients with moderate to severe ulcerative colitis. Gastroenterology. 2013.

70. Sandborn WJ, Feagan BG, Marano C, et al. Subcutaneous golimumab maintains clinical response in patients with moderate-to-severe ulcerative colitis. Gastroenterology. 2013.

71. Gordon FH, Lai CW, Hamilton MI, et al. A randomized placebocontrolled trial of a humanized monoclonal antibody to $\alpha 4$ integrin in active Crohn's disease. Gastroenterology. 2001;121:268-274.

72. Ghosh S, Goldin E, Gordon FH, et al. Natalizumab for active Crohn's disease. $N$ Engl J Med. 2003;348:24-32.

73. Sandborn WJ, Colombel JF, Enns R, et al. Natalizumab induction and maintenance therapy for Crohn's disease. $N$ Engl J Med. 2005;353:1912-1925.

74. Feagan BG, Greenberg GR, Wild G, et al. Treatment of active Crohn's disease with MLNO002, a humanized antibody to the a4ß7 integrin. Clin Gastroenterol Hepatol. 2008;6:1370-1377.

75. Feagan BG, Rutgeerts P, Sands BE, et al. Vedolizumab as induction and maintenance therapy for ulcerative colitis. $N$ Engl J Med. 2013;369:699-710.

76. Sandborn WJ, Feagan BG, Rutgeerts P, et al. Vedolizumab as induction and maintenance therapy for Crohn's disease. $N \mathrm{Engl}$ J Med. 2013;369:711-721.

77. Sandborn WJ, Feagan BG, Fedorak RN, et al. A randomized trial of Ustekinumab, a human interleukin-12/23 monoclonal antibody, in patients with moderate-to-severe Crohn's disease. Gastroenterology. 2008;135:1130-1141. 
78. Sandborn WJ, Gasink C, Gao LL, et al. Ustekinumab induction and maintenance therapy in refractory Crohn's disease. $N$ Engl $J$ Med. 2012;367:1519-1528.

79. US Food and Drug Administration CfDEaR. Biologics License Application Approval: Stelara (ustekinumab). 2016.

80. Hooks MA, Wade CS, Millikan WJ Jr. Muromonab CD-3: a review of its pharmacology, pharmacokinetics, and clinical use in transplantation. Pharmacotherapy. 1991;11:26-37.

81. Millis JM, McDiarmid SV, Hiatt JR, et al. Randomized prospective trial of OKT3 for early prophylaxis of rejection after liver transplantation. Transplantation. 1989;47:82-88.

82. Lin CC, Chuang FR, Lee CH, et al. The renal-sparing efficacy of basiliximab in adult living donor liver transplantation. Liver Transpl. 2005;11:1258-1264.

83. Penninga L, Wettergren A, Wilson $\mathrm{CH}$, Chan AW, Steinbruchel DA, Gluud C. Antibody induction versus corticosteroid induction for liver transplant recipients. Cochrane Database Syst Rev. 2014:Cd010252.

84. Kovarik JM, Nashan B, Neuhaus P, et al. A population pharmacokinetic screen to identify demographic-clinical covariates of basiliximab in liver transplantation. Clin Pharmacol Ther. 2001;69:201-209.

85. Goralczyk AD, Hauke N, Bari N, Tsui TY, Lorf T, Obed A. Interleukin 2 receptor antagonists for liver transplant recipients: a systematic review and meta-analysis of controlled studies. Hepatology. 2011;54:541-554.

86. Crins ND, Rover C, Goralczyk AD, Friede T. Interleukin-2 receptor antagonists for pediatric liver transplant recipients: a systematic review and meta-analysis of controlled studies. $P e$ diatr Transplant. 2014;18:839-850.

87. Rutgeerts PJ, Fedorak RN, Hommes DW, et al. A randomised phase I study of etrolizumab (rhuMAb $\beta 7$ ) in moderate to severe ulcerative colitis. Gut. 2013;62:1122-1130.

88. Vermeire S, O'Byrne S, Keir M, et al. Etrolizumab as induction therapy for ulcerative colitis: a randomised, controlled, phase 2 trial. Lancet. 2014;384:309-318.

89. Gao Q, Meijer MJ, Kubben FJ, et al. Expression of matrix metalloproteinases-2 and -9 in intestinal tissue of patients with inflammatory bowel diseases. Dig Liver Dis. 2005;37: 584-592.

90. Annahazi A, Molnar T, Farkas K, et al. Fecal MMP-9: a new noninvasive differential diagnostic and activity marker in ulcerative colitis. Inflamm Bowel Dis. 2013;19:316-320.

91. Chingcuanco F, Segal JB, Kim SC, Alexander GC. Bioequivalence of Biosimilar tumor necrosis factor-alpha inhibitors compared with their reference biologics: a systematic review. Ann Intern Med. 2016.

92. Smits LJ, Derikx LA, de Jong DJ, et al. Clinical outcomes following a switch from Remicade ${ }^{\circledR}$ to the biosimilar CT-P13 in inflammatory bowel disease patients: a prospective observational cohort study. J Crohns Colitis. 2016.

93. Kolar D, Brotlik M, Hruba V, et al. Switching of patients with inflammatory bowel disease from original infliximab (Remicade $^{\circledR}$ ) to biosimilar infliximab (Remsima ${ }^{\mathrm{TM}}$ ) is effective and safe. In: European Crohn's and Colitis Organisation, Amsterdam, Netherlands; 2016.

94. Bettey L, Underhill C, Callaghan J, Rush M, Ahmed I, Cummings, F. Outcomes of a managed switching programme changing IBD patients established on originator infliximab to biosimilar infliximab. In: European Crohn's and Colitis Organisation, Amsterdam, Netherlands; 2016.

95. Gecse KB, Lovasz BD, Farkas K, et al. Efficacy and safety of the biosimilar infliximab CT-P13 treatment in inflammatory bowel diseases: a prospective, multicentre, nationwide cohort. $J$ Crohns Colitis. 2016;10:133-140.
96. Farkas K, Rutka M, Golovics PA, et al. Efficacy of infliximab biosimilar CT-P13 induction therapy on mucosal healing in ulcerative colitis. J Crohns Colitis. 2016.

97. Sieczkowska J, Jarzebicka D, Banaszkiewicz A, et al. Switching between infliximab originator and biosimilar in paediatric patients with inflammatory bowel disease. Preliminary observations. J Crohns Colitis. 2016;10:127-132.

98. Ben-Horin S, Yavzori M, Benhar I, et al. Cross-immunogenicity: antibodies to infliximab in Remicade-treated patients with IBD similarly recognise the biosimilar Remsima. Gut. 2016;65:1132-1138.

99. US Food and Drug Administration AAC. FDA Briefing Document: ABP 501, a Proposed Biosimilar to Humira (adalimumab). 2016

100. US Food and Drug Administration CfDEaR. Approval Package: Amjetiva (adalimumab-atto). Application Number 761024Orig1s000. 2016.

101. Ananthakrishnan AN. Clostridium difficile infection: epidemiology, risk factors and management. Nat Rev Gastroenterol Hepatol. 2011;8:17-26.

102. Qiu H, Cassan R, Johnstone D, et al. Novel Clostridium difficile anti-toxin (TcdA and TcdB) humanized monoclonal antibodies demonstrate in vitro neutralization across a broad spectrum of clinical strains and in vivo potency in a hamster spore challenge model. PLoS ONE. 2016;11:e0157970.

103. Koon HW, Shih DQ, Hing TC, et al. Human monoclonal antibodies against Clostridium difficile toxins A and B inhibit inflammatory and histologic responses to the toxins in human colon and peripheral blood monocytes. Antimicrob Agents Chemother. 2013;57:3214-3223.

104. Yang Z, Ramsey J, Hamza T, et al. Mechanisms of protection against Clostridium difficile infection by the monoclonal antitoxin antibodies actoxumab and bezlotoxumab. Infect Immun. 2015;83:822-831.

105. Lowy I, Molrine DC, Leav BA, et al. Treatment with monoclonal antibodies against Clostridium difficile toxins. $N$ Engl $J$ Med. 2010;362:197-205.

106. US Food and Drug Administration ADAC. FDA Briefing Document: Bezlotoxumab Injection. 2016.

107. Liaskou E, Karikoski M, Reynolds GM, et al. Regulation of mucosal addressin cell adhesion molecule 1 expression in human and mice by vascular adhesion protein 1 amine oxidase activity. Hepatology. 2011;53:661-672.

108. Grant AJ, Lalor PF, Hubscher SG, Briskin M, Adams DH. MAdCAM-1 expressed in chronic inflammatory liver disease supports mucosal lymphocyte adhesion to hepatic endothelium (MAdCAM-1 in chronic inflammatory liver disease). Hepatology. 2001;33:1065-1072.

109. Halilbasic E, Fuchs C, Hofer H, Paumgartner G, Trauner M. Therapy of primary sclerosing cholangitis-today and tomorrow. Dig Dis. 2015;33:149-163.

110. Ratziu V. Novel pharmacotherapy options for NASH. Dig Dis Sci. 2016;61:1398-1405. doi:10.1007/s10620-016-4128-z

111. Stein ML, Collins MH, Villanueva JM, et al. Anti-IL-5 (mepolizumab) therapy for eosinophilic esophagitis. J Allergy Clin Immunol. 2006;118:1312-1319.

112. Assa'ad AH, Gupta SK, Collins MH, et al. An antibody against IL-5 reduces numbers of esophageal intraepithelial eosinophils in children with eosinophilic esophagitis. Gastroenterology. 2011;141:1593-1604.

113. Straumann A, Conus S, Grzonka P, et al. Anti-interleukin-5 antibody treatment (mepolizumab) in active eosinophilic oesophagitis: a randomised, placebo-controlled, double-blind trial. Gut. 2010;59:21-30.

114. van der Valk ME, Mangen MJ, Leenders M, et al. Healthcare costs of inflammatory bowel disease have shifted from 
hospitalisation and surgery towards anti-TNFalpha therapy: results from the COIN study. Gut. 2014;63:72-79.

115. Gleason PP, Alexander GC, Starner CI, et al. Health plan utilization and costs of specialty drugs within 4 chronic conditions. J Manag Care Pharm (JMCP). 2013;19:542-548.

116. Park KT, Sin A, Wu M, Bass D, Bhattacharya J. Utilization trends of anti-TNF agents and health outcomes in adults and children with inflammatory bowel diseases: a single-center experience. Inflamm Bowel Dis. 2014;20:1242-1249.

117. Yokomizo L, Limketkai B, Park KT. Cost-effectiveness of adalimumab, infliximab or vedolizumab as first-line biological therapy in moderate-to-severe ulcerative colitis. BMJ Open Gastroenterol. 2016;3:e00093.
118. Steenholdt C, Brynskov J, Thomsen OO, et al. Individualised therapy is more cost-effective than dose intensification in patients with Crohn's disease who lose response to anti-TNF treatment: a randomised, controlled trial. Gut. 2014;63:919-927.

119. Roblin X, Attar A, Lamure M, et al. Cost savings of anti-TNF therapy using a test-based strategy versus an empirical dose escalation in Crohn's disease patients who lose response to infliximab. J Mark Access Health Policy. 2015;3.

120. Ananthakrishnan AN, Korzenik JR, Hur C. Can mucosal healing be a cost-effective endpoint for biologic therapy in Crohn's disease? A decision analysis. Inflamm Bowel Dis. 2013;19:37-44. 